\title{
Autoimmune hepatitis: Focusing on treatments other than steroids
}

\author{
Albert J Czaja MD
}

AJ Czaja. Autoimmune hepatitis: Focusing on treatments other than steroids. Can J Gastroenterol 2012;26(9):615-620.

BACKGROUND: Corticosteroid therapy has been the time-honoured treatment for autoimmune hepatitis; however, the emergence of new immunosuppressive agents has afforded opportunities to improve or replace the standard regimens.

OBJECTIVE: To describe technological advances and feasible treatment interventions that promise to supplant the current generation of corticosteroids.

METHODS: A review of the MEDLINE database for published experiences from 1984 to 2011 was conducted.

RESULTS: Cyclosporine and tacrolimus have been uniformly successful as salvage therapies for steroid-refractory autoimmune hepatitis. Ten reports of cyclosporine therapy involving 133 patients had positive outcomes in 93\%, whereas therapy with tacrolimus in three reports involving 41 patients had positive outcomes in 98\%. Salvage therapy with mycophenolate mofetil had a favourable outcome in $47 \%$, especially in patients with azathioprine intolerance. Front-line therapy with mycophenolate mofetil normalized liver parameters in $88 \%$ and allowed corticosteroid tapering in $58 \%$. Front-line therapy with budesonide combined with azathioprine for six months normalized liver parameters more frequently (47\% versus 18\%) and with fewer side effects ( $28 \%$ versus $53 \%$ ) than prednisone combined with azathioprine. Monoclonal antibodies to CD3 and recombinant cytotoxic $\mathrm{T}$ lymphocyte antigen 4 fused with immunoglobulin represent feasible molecular interventions for study in autoimmune hepatitis. DISCUSSION: Nonstandard drug therapies must be used in highly selected clinical situations including steroid failure (calcineurin inhibitors), azathioprine intolerance (mycophenolate mofetil), and mild disease or fragile patients (budesonide combined with azathioprine). Molecular interventions for autoimmune hepatitis are feasible for study because of their use in other immune-mediated diseases. CONCLUSION: Opportunities to improve or replace standard corticosteroid regimens have emerged.

Key Words: Autoimmune; Front-line; Hepatitis; Molecular; Salvage; Therapy

Drednisone (or prednisolone), alone or in a lower dose combined with azathioprine, is the standard treatment for autoimmune hepatitis (1); this therapy has been a benchmark for decades (2-4). At least $70 \%$ of treated patients experience clinical, laboratory and histological improvement within 24 months $(3,5,6)$. Ten- and 20 -year life expectancies are normal $(5,7)$, and hepatic fibrosis is prevented or reduced in $79 \%(8,9)$. These achievements, however, have been outweighed by deficiencies in the current regimens including treatment-ending side effects in 13\% (10), refractory disease (treatment failure) in 7\% (11), incomplete response in $13 \%$ (12) and relapse after drug withdrawal in $50 \%$ to $86 \%(13,14)$.

Only recently has the emergence of powerful immunosuppressive agents, mainly from liver transplantation, challenged the supremacy of the corticosteroid regimens (15-17). Drugs outside of the standard repertoire now promise greater immune suppression than conventional

\section{L'hépatite auto-immune : cibler d'autres traitements que les stéroïdes}

HISTORIQUE : La corticothérapie est le traitement immuable de l'hépatite auto-immune. Cependant, l'émergence de nouveaux immunosuppresseurs donne l'occasion d'améliorer ou de remplacer les médicaments habituels.

OBJECTIF : Décrire les progrès technologiques et les interventions thérapeutiques possibles qui promettent de supplanter la génération actuelle de corticoïdes.

MÉTHODOLOGIE : Les chercheurs ont procédé à une analyse de la base de données MEDLINE afin d'extraire les expériences publiées entre 1984 et 2011.

RÉSULTATS : La cyclosporine et le tacrolimus ont toujours été efficaces comme thérapies de rattrapage de l'hépatite auto-immune réfractaire aux stéroïdes. Sept rapports de traitements à la cyclosporine auprès de 33 patients ont fait foi d'une issue positive dans $82 \%$ des cas, tandis que trois rapports au sujet de 41 patients subissant un traitement au tacrolimus ont souligné une issue positive dans $98 \%$ des cas. La thérapie de rattrapage au mofétil mycophénolate a eu une issue positive dans $47 \%$ des cas, notamment chez des patients intolérants à l'azathioprine. La thérapie de première ligne au mofétil mycophénolate normalise les paramètres hépatiques dans $88 \%$ des cas et permet de réduire graduellement la corticothérapie dans $58 \%$ des cas. La thérapie de première ligne au budésonide associée à l'azathioprine administrée pendant six mois a normalisé les paramètres hépatiques plus fréquemment ( $47 \%$ par rapport à $18 \%$ ) et causé moins d'effets secondaires (28\% par rapport à $53 \%$ ) que la prednisone associée à l'azathioprine. Les anticorps monoclonaux anti- $\mathrm{CD}_{3}$ et l'antigène 4 du lymphocyte $\mathrm{T}$ cytotoxique recombinant fusionnés avec l'immunoglobuline représentent des interventions moléculaires possibles en vue d'études sur l'hépatite autoimmune.

EXPOSÉ : Il faut utiliser les médicothérapies non standard dans des situations cliniques extrêmement bien sélectionnées, y compris l'échec des stéroïdes (inhibiteurs de la calcineurine), l'intolérance à l'azathioprine (mofétilmycophénolate) et une maladie bénigne ou des patients fragiles (budésonide associée à l'azathioprine). Il est possible d'étudier des interventions moléculaires pour le traitement de l'hépatite auto-immune en raison de leur utilisation dans d'autres maladies à médiation immunitaire. CONCLUSION : Des possibilités d'améliorer ou de remplacer la corticothérapie standard ont vu le jour.

medications, offer site-specific actions and satisfactory patient tolerance $(15,17)$. Site-specific molecular interventions are also feasible because of improved understanding of the critical pathogenic disease pathways and technological advances that now enable modulation of these pathways $(16,17)$. Furthermore, successes in animal models and humans with other immune-mediated diseases have primed these molecular interventions for study in autoimmune hepatitis (16-18).

The aim of the present review is to describe contemporary advances and feasible treatment strategies that promise to supplant the current generation of corticosteroids. The new nonstandard drugs have emerged as front-line and salvage therapies, and include calcineurin inhibitors (cyclosporine and tacrolimus), a next-generation purine antagonist (mycophenolate mofetil) and an alternative glucocorticoid agent (budesonide) (17). These agents have been assessed mainly in small, single-centre studies for off-label indications. The potential

Division of Gastroenterology and Hepatology, Mayo Clinic College of Medicine, Rochester, Minnesota USA

Correspondence: Dr Albert J Czaja, Mayo Clinic College of Medicine, 200 First Street Southwest, Rochester, Minnesota 55905, USA.

Telephone 507-284-8118, fax 507-284-0538, e-mail czaja.albert@mayo.edu

Received for publication December 9, 2011. Accepted December 20, 2011 


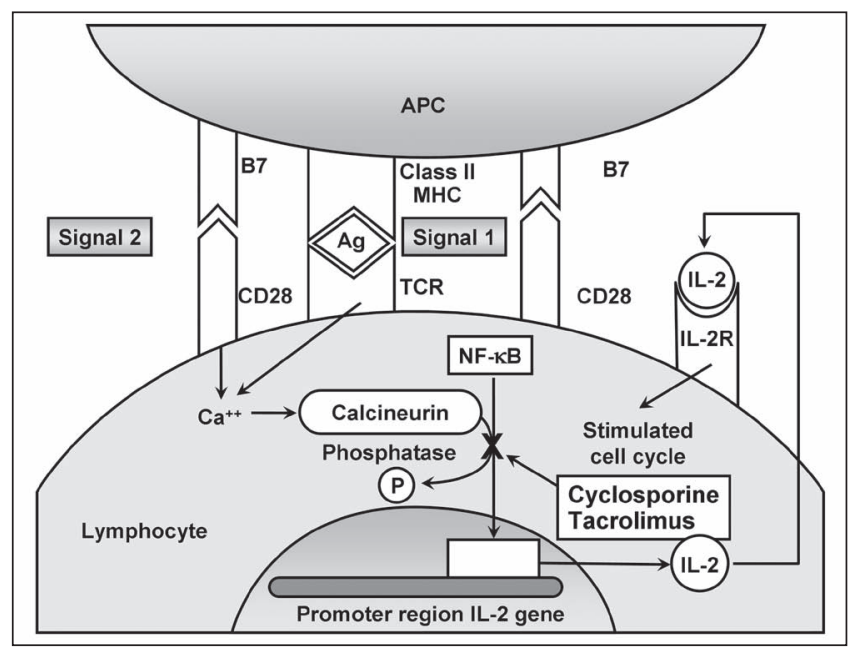

Figure 1) Mechanisms of action of calcineurin inhibitors within lymphocytes. Lymphocyte activation requires recognition of the antigen $(\mathrm{Ag})$ presented by the class II molecule of the major histocompatibility complex (MHC) on the surface of the antigen presenting cell (APC) by the T cell antigen receptor (TCR) of the lymphocyte (Signal 1). Binding of the B7 ligands on the surface of the APC to CD28 molecules on the surface of the lymphocyte completes the second costimulatory signal (signal 2) and activates the lymphocyte. Lymphocyte activation releases calcium $\left(\mathrm{Ca}^{2+}\right)$, which activates calcineurin and stimulates lymphocyte proliferation. Cyclosporine and tacrolimus each block calcineurin-mediated activation of nuclear factor-kappa B (NF-кB) via a phosphatase $(P)$ pathway within lymphocytes and thereby impair production of interleukin (IL)-2. Activation of the IL-2 receptor (IL-2R) is impaired; cell cycles are stalled; and lymphocyte proliferation is blunted

molecular interventions include monoclonal antibodies that interfere with the immune response and recombinant molecules that favourably modulate the cytokine pathways responsible for lymphocyte differentiation and proliferation (15-17). The challenges are to incorporate these new, nonstandard, off-label medications into safe and effective management strategies, and to facilitate the rigorous study of these emerging molecular interventions.

\section{CALCINEURIN INHIBITORS}

Calcineurin activates nuclear factor- $\kappa \mathrm{B}$ via a pathway dependent on phosphatase activity (Figure 1) (19). The activated nuclear factor binds to promoter regions of the interleukin (IL)-2 gene and increases transcription of IL-2. In turn, IL-2 stimulates the cell cycle by binding to the IL-2 receptor, and lymphocytes proliferate along a type 1 cytokine pathway. Cyclosporine and tacrolimus are calcineurin inhibitors that impair phosphatase activity, interfere with the proliferation of lymphocytes and blunt cell-mediated immune responses. Cyclosporine and tacrolimus have each been used in autoimmune hepatitis patients, primarily as salvage therapies for steroid-refractory disease $(15,17)$.

\section{Cyclosporine}

Cyclosporine has been used as a salvage therapy for autoimmune hepatitis since 1985 (20). Ten reports involving 133 patients over the past 26 years $(20-26)$ indicated that a positive response of any degree was achieved in $93 \%$, and a negative response, defined as no response or drug intolerance, was reported in 7\% (Table 1). In the most recent experience involving 19 patients treated for 26 weeks with cyclosporine (Neoral, Novartis Pharma, Switzerland) $2 \mathrm{mg} / \mathrm{kg}$ to $5 \mathrm{mg} / \mathrm{kg}$ daily (26), serum aminotransferase levels decreased significantly, histological activity indexes improved and the medication was well tolerated.

\section{Tacrolimus}

Tacrolimus has been used as a salvage therapy for autoimmune hepatitis since 1995 (27). The starting dose of tacrolimus in the various studies has been as low as $0.5 \mathrm{mg} /$ day $(28,29)$ to as high as $3 \mathrm{mg}$ twice/day (27). The combined experience with this drug in autoimmune hepatitis consists of three reports involving 41 patients over the past 16 years (27-29) (Table 1$)$. A positive response of any degree was reported in $98 \%$, and a negative response, defined as no response or treatment-ending drug intolerance, was reported in $2 \%$.

The success of the calcineurin inhibitors as a salvage therapy for autoimmune hepatitis has been impressive, but the overall reported clinical experience with these agents has been lacking. Calcineurin inhibitors still lack a uniform dosing schedule, an acceptable safety profile and an established monitoring protocol for autoimmune hepatitis despite their longstanding empirical use in this disease. The paucity of reports may reflect the gradual unendorsed assimilation of these drugs into current clinical practice or the emergence of alternative, more promising treatment options. Efforts to launch large, multicentre, clinical trials have been frustrated by low patient recruitment. Calcineurin inhibitors remain empirical, off-label treatments reserved for steroid-refractory disease.

\section{MYCOPHENOLATE MOFETIL}

Mycophenolate mofetil is a next-generation purine antagonist that has been used as a front-line drug and as a salvage agent for autoimmune hepatitis $(15,17)$. It is a prodrug that is hydrolyzed by liver esterases to mycophenolic acid, which in turn acts as a reversible noncompetitive inhibitor of inosine monophosphate dehydrogenase (30) (Figure 2). Mycophenolate mofetil can thereby selectively impair the synthesis of purine-based nucleotides, inhibit the creation of new DNA and impair the proliferation of activated lymphocytes. Its activation and elimination are independent of the thiopurine methyltransferase pathway.

Eleven small single-centre experiences have indicated that mycophenolate mofetil is effective in problematic patients in doses ranging from $0.5 \mathrm{~g} /$ day to $3 \mathrm{~g} /$ day (31-41). In a compilation of four experiences reported over the past three years $(36-38,41)$, a positive response of any degree was recorded in $47 \%$ of treated patients, whereas a negative response, defined as no response or drug intolerance, occurred in 53\% (Table 1). Complete corticosteroid withdrawal was possible in $40 \%$ of patients included in the 11 studies, and the overall frequency of treatment-ending side effects was $15 \%$. Patients treated with mycophenolate mofetil because of azathioprine intolerance demonstrated improvement more frequently than patients treated for refractory liver disease $(58 \%$ versus $12 \%)(37,40,41)$, whereas children with autoimmune hepatitis and sclerosing cholangitis were nonresponders (39).

Mycophenolate mofetil has also been used as a front-line therapy in treatment-naive patients. Of 59 previously untreated individuals with autoimmune hepatitis who received mycophenolate mofetil for up to 92 months, $88 \%$ experienced normalized serum aminotransferase and gamma-globulin levels (usually within three months) and $12 \%$ experienced partial response (42). Corticosteroids were withdrawn in $58 \%$ (usually within eight months) and serious side effects occurred in $3 \%$. Mycophenolate mofetil can be administered effectively and safely as a front-line treatment, but the reasons for preferring this treatment as a front-line strategy are unclear.

The most common side effects of treatment with mycophenolate mofetil in autoimmune hepatitis patients have been gastrointestinal discomfort (nausea, diarrhea and abdominal pain) (11\%), rash (including skin cancers) (7\%), fatigue (7\%) and leukopenia (1\%) $(41,42)$. The frequency of side effects has ranged from $3 \%$ to $33 \%$ $(41,42)$, and the frequency of treatment-ending complications has been as high as 13\% (41). Mycophenolate mofetil has been designated a category D drug in pregnancy by the United States Food and Drug Administration.

The clinical applications of mycophenolate mofetil in autoimmune hepatitis have been based on outcomes in fewer than 300 patients who have been treated with varying doses in different medical centres over the past 11 years (31-42). This limited and disparate experience underscores the need for a highly individualized and carefully monitored 
TABLE 1

Alternative drugs to prednisone for autoimmune hepatitis

\begin{tabular}{|c|c|c|c|}
\hline Drug, dose (reference[s]) & Mechanism of action (reference[s]) & Clinical indication (reference[s]) & Outcomes (reference[s]) \\
\hline $\begin{array}{l}\text { Cyclosporine, } 2 \text { mg/kg/day to } \\
5 \mathrm{mg} / \mathrm{kg} / \text { day (26) }\end{array}$ & $\begin{array}{l}\text { Calcineurin inhibitor (19) } \\
\text { Impairs NF-KB (19) } \\
\text { Reduces IL-2 (19) } \\
\text { Impairs Iymphocyte proliferation (19) }\end{array}$ & Steroid-failure (20-26) & $\begin{array}{l}\text { Composite results (20-26): } \\
\text { - Improvement, } 93 \% \\
\text { - Failure/side effects, } 7 \%\end{array}$ \\
\hline $\begin{array}{l}\text { Tacrolimus, } 0.5 \mathrm{mg} / \mathrm{day} \text { to } \\
3 \mathrm{mg} \text { twice/day (27-29) }\end{array}$ & $\begin{array}{l}\text { Calcineurin inhibitor (19) } \\
\text { Impairs NF-KB (19) } \\
\text { Reduces IL-2 (19) } \\
\text { Impairs Iymphocyte proliferation (19) }\end{array}$ & Steroid-failure (27-29) & $\begin{array}{l}\text { Composite results (27-29): } \\
\text { - Improvement, } 98 \% \\
\text { - Failure/side effects, } 2 \%\end{array}$ \\
\hline $\begin{array}{l}\text { Mycophenolate mofetil, } 0.5 \text { g/day to } \\
3 \mathrm{~g} / \text { day (41) }\end{array}$ & $\begin{array}{l}\text { Purine antagonist }(30) \\
\text { Inhibits inosine monophosphate } \\
\text { dehydrogenase }(30) \\
\text { Limits purine nucleotides }(30) \\
\text { Impairs lymphocyte proliferation (30) }\end{array}$ & $\begin{array}{l}\text { Azathioprine intolerance (main) }(37,41) \\
\text { Steroid-failure (less effective) }(37,41) \\
\text { Front-line therapy (uncertain preference) }(42)\end{array}$ & $\begin{array}{l}\text { Salvage outcomes }(31-41) \text { : } \\
\text { - Overall improvement, } 47 \% \\
\text { - Azathioprine intolerance, } 58 \% \\
\text { - Refractory disease, } 12 \% \\
\text { - Failure or side effects, } 53 \% \\
\text { - Steroid withdrawal, } 40 \% \\
\text { - Serious side effects, } 3-33 \% \\
\text { Front-line outcomes }(42): \\
\text { - Complete response, } 88 \% \\
\text { - Partial response, } 12 \% \\
\text { - Steroid withdrawal, } 58 \% \\
\text { - Serious side effects, } 3 \%\end{array}$ \\
\hline $\begin{array}{l}\text { Budesonide, } 3 \mathrm{mg} \text { three times/day } \\
\text { combined with azathioprine (47) }\end{array}$ & $\begin{array}{l}\text { Anti-inflammatory }(46) \\
\text { High hepatic clearance (48) } \\
\text { Inactive metabolites (48) }\end{array}$ & $\begin{array}{l}\text { Front-line therapy (47) } \\
\text { No cirrhosis (53) } \\
\text { Mild disease (49) } \\
\text { Prednisone risk (49) }\end{array}$ & $\begin{array}{l}\text { After } 6 \text { months of therapy ( } 47) \text { : } \\
\text { - Laboratory normalization, } 47 \% \\
\text { - Side effects, } 28 \%\end{array}$ \\
\hline
\end{tabular}

IL-2 Interleukin-2; NF-KB Nuclear factor kappa-B

management strategy when using mycophenolate mofetil off label. Mycophenolate mofetil is six to seven times more expensive than azathioprine $(43,44)$; treatment ending side effects occur in $3 \%$ to $13 \%$ $(41,42)$; most patients require continuous corticosteroid therapy; the duration of treatment is indefinite; and the drug is more effective in rescuing patients with azathioprine intolerance than steroid-refractory liver disease $(37,40,41)$. Mycophenolate mofetil has a limited and evolving off-label role in autoimmune hepatitis, and its use as a salvage therapy for azathioprine intolerance is currently its most effective application (45).

\section{BUDESONIDE}

Budesonide is a next-generation glucocorticoid that has $>90 \%$ first-pass clearance in the liver, with metabolites devoid of glucocorticoid activity (46) (Table 1). Its steroidal nature does not disqualify its consideration in the present review because budesonide promises to move current therapies away from reliance on prednisone or prednisolone. Furthermore, budesonide is the first drug in autoimmune hepatitis to be assessed in a large randomized clinical trial in more than 40 years (47). In this regard, it has legitimized its place in the treatment algorithm to a greater degree than the true alternatives to traditional steroids.

Budesonide was first used in the treatment of autoimmune hepatitis in 1994 (48) and, over the past 17 years, six studies involving 162 patients, 100 of whom were enrolled in a randomized clinical trial (47), have helped define its role in autoimmune hepatitis (47-52) (Table 1). Early experiences indicated difficulties in using this drug as a salvage agent in prednisone-dependent patients (49). Attempts to switch from prednisone to budesonide were complicated by severe withdrawal arthralgias and typical corticosteroid-induced side effects (49). Altered hepatic metabolism in patients with cirrhosis was associated with the development of serious drug-related complications (53); immune-mediated diseases concurrent with autoimmune hepatitis could exacerbate (49); and flares of autoimmune hepatitis during therapy were always possible (54). These experiences characterized the ideal target population for the drug and directed its use toward treatment-naive, noncirrhotic and uncomplicated patients.

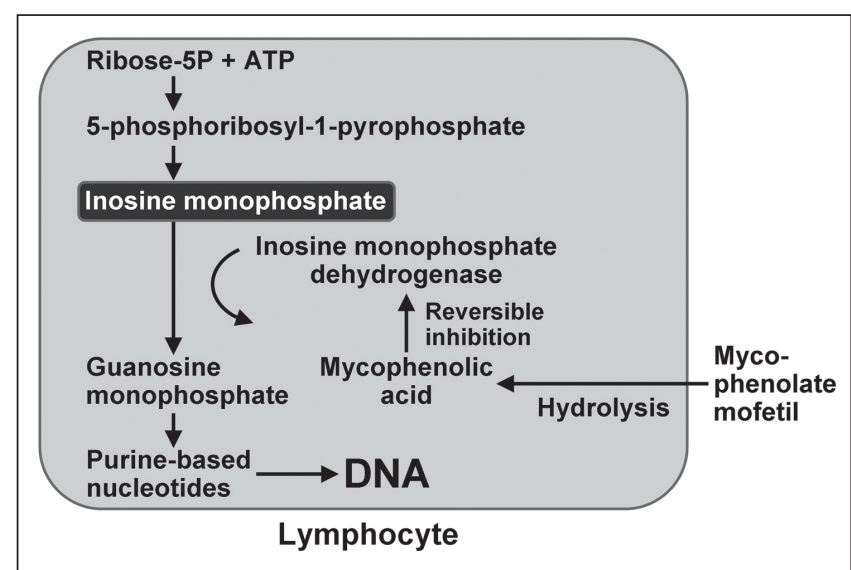

Figure 2) Mechanisms of action of mycophenolate mofetil within lymphocytes. Mycophenolate mofetil is hydrolyzed to mycophenolic acid, which is a noncompetitive reversible inhibitor of inosine monophosphate dehydrogenase. The synthesis of purine-based nucleotides is impaired, the creation of new DNA is reduced and lymphocyte proliferation is inhibited. Inosine monophosphate is produced from ribose-5 phosphate (ribose-5P) and adenosine triphosphate (ATP)

A large randomized clinical trial involving 203 patients with these attributes subsequently demonstrated the advantages of budesonide over conventional prednisone-based treatment (47). Budesonide (3 mg three times/day) combined with azathioprine ( $1 \mathrm{mg} / \mathrm{kg} / \mathrm{day}$ to $2 \mathrm{mg} / \mathrm{kg} / \mathrm{day})$ normalized serum aminotransferase levels more often ( $47 \%$ versus $18 \%$ ) and with fewer side effects (28\% versus $53 \%$ ) than the standard regimen of prednisone ( $40 \mathrm{mg}$ daily, tapered to $10 \mathrm{mg}$ daily) combined with azathioprine ( $1 \mathrm{mg} / \mathrm{kg} /$ day to $2 \mathrm{mg} / \mathrm{kg} /$ day $)$ when administered for six months (47). The frequency of histological resolution and the durability of the response remain unknown, and the low frequency of 
TABLE 2

Future feasible drug alternatives for autoimmune hepatitis (AIH)

\begin{tabular}{|c|c|c|}
\hline Feasible molecular intervention & Mechanisms of action (reference[s]) & Precedents in human diseases (reference[s]) \\
\hline \multirow{3}{*}{$\begin{array}{l}\text { Nonmitogenic monoclonal antibodies to CD3 } \\
\text { (anti-CD3) }\end{array}$} & Targets T cell antigen receptor $(17,55)$ & Type 1 diabetes $(17,55)$ \\
\hline & Induces apoptosis of lymphocytes (17) & \multirow{2}{*}{$\begin{array}{l}\text { Few side effects (fever, rash, anemia, EBV } \\
\text { infection) (17) }\end{array}$} \\
\hline & Releases TGF- $\beta$ (17) & \\
\hline
\end{tabular}

Monoclonal antibodies to CD20 (anti-CD20)

Monoclonal antibodies to TNF- $\alpha$ (anti-TNF- $\alpha$ ) or its receptor (etanercept)
Induces regulatory T cells (17)

Suppresses immune response (17)

Targets CD20 expressed on B cells (17)

Depletes B lymphocytes (17)

Impairs type 2 cytokine pathway (17)

Interferes with antibody-dependent cell-mediated cytotoxcities (17)

Interferes with type 1 cytokine pathway (15-17) Impairs proliferation of cytotoxic T cells (15-17)

\begin{abstract}
Recombinant cytotoxic T lymphocyte antigen 4 fused with immunoglobulin
\end{abstract}

Recombinant interleukin-10

\author{
Resembles CD28 on lymphocyte (15-17) \\ Binds B7 ligands on APC (15-17) \\ Interferes with second costimulatory signal of \\ lymphocyte activation (15-17) \\ Counters type 2 cytokine path (15-17) \\ Reduces TNF- $\alpha$ (15-17) \\ Decreases inflammation (15-17) \\ Impairs differentiation and proliferation of \\ T lymphocytes (15-17)
}

\author{
Hematological malignancies (17) \\ Rheumatoid arthritis, ITP (17) \\ AlH and cryoglobulinemia (17) \\ AlH and B cell lymphoma (17) \\ Rare serious toxicities (progressive multifocal \\ leukoencephalopathy) (17) \\ Crohn disease $(16,17)$ \\ Rheumatoid arthritis $(16,17)$ \\ Alcoholic hepatitis (ineffective) $(16,17)$ \\ NAFLD (ineffective) $(16,17)$ \\ Serious toxicities (infection, death, lung disease, \\ SLE, AlH) $(16,17)$ \\ Rheumatoid arthritis (15-17) \\ Mismatched bone marrow transplantation (15-17) \\ Multiple sclerosis (15-17) \\ Few side effects (infection) $(16,17)$ \\ Chronic hepatitis C (15-17) \\ Inflammatory bowel disease (15-17) \\ Few dose-related side effects (anemia, \\ thrombocytopenia, fever, chills, myalgias, \\ headache) $(16,17)$
}

Numbers in parentheses indicate reference(s). APC Antigen presenting cell; EBV Epstein-Barr virus; ITP Idiopathic thrombocytopenic purpura; NAFLD Nonalcoholic fatty liver disease; SLE Systemic lupus erythematosus; TNF- $\alpha$ Tumour necrosis factor-alpha; TGF- $\beta$ Transforming growth factor-beta

response (only 18\%) and the high frequency of side effects (53\%) in the patients treated with the standard regimen remain unexplained.

In combination with azathioprine, budesonide is emerging as an alternative front-line treatment for autoimmune hepatitis, but its off-label use must be cautious and conservative. There is still insufficient experience with this drug in treating the diverse presentations of autoimmune hepatitis to justify its blanket substitution for prednisone or prednisolone. Treatment appears to be best suited for treatment-naive, noncirrhotic and uncomplicated patients, and it has appeal as a first-line therapy in patients with asymptomatic, mild autoimmune hepatitis in whom the benefit-to-risk ratio of conventional prednisone treatment may be low. Patients with preexistent osteopenia, hypertension, diabetes, obesity and emotional instability may be other candidates for the budesonide-azathioprine combination.

\section{FEASIBLE MOLECULAR INTERVENTIONS}

Site-specific molecular interventions are now feasible in autoimmune hepatitis mainly because of successes already achieved in other immune-mediated diseases $(16,17)$ (Table 2). These interventions include the use of monoclonal antibodies and recombinant molecules that alter lymphocyte activation pathways, differentiation and proliferation. They constitute new treatment opportunities that are based on available technology and ongoing experiences in animal models and humans with autoimmune diseases. Other interventions, including synthetic peptides that block autoantigen display, oral tolerization against triggering antigens, $T$ cell vaccination against cytotoxic $T$ cell clones, adoptive transfer of regulatory $\mathrm{T}$ cells and silencing of genes that promote the autoimmune reaction, are feasible, but they are either untried, too preliminary, or inconsistently effective in animals or humans $(16,17)$.

\section{Monoclonal antibodies}

Nonmitogenic monoclonal antibodies to CD3 target the $\mathrm{T}$ cell antigen receptor of liver-infiltrating cytotoxic $\mathrm{T}$ cells and induce apoptosis (55) (Table 2). This treatment has already been used successfully in animal models and humans with type 1 diabetes and awaits study in autoimmune hepatitis. Antibodies to CD20 can blunt clonal expansion of B cells and dampen antibody-mediated forms of cytotoxicity. Rituximab has already been used successfully in patients with rheumatoid arthritis (17). Monoclonal antibodies to tumour necrosis factor-alpha or its receptor are also feasible, but enthusiasm for this intervention has been dampened by the potential for serious toxicities $(16,17)$. Anti-CD3 is the most promising intervention in this category because of its relevance to the pathogenic mechanisms of autoimmune hepatitis and its success in other immune-mediated human diseases (55).

\section{Recombinant molecules}

Recombinant cytotoxic T lymphocyte antigen 4 fused with immunoglobulin blocks the second costimulatory signal for immunocyte activation and can blunt the immune response $(16,17,55)$ (Table 2). Abatacept is already approved in the United States and Europe for rheumatoid arthritis, and awaits study in autoimmune hepatitis. Recombinant IL-10 has anti-inflammatory effects that counterbalance the type 1 cytokine pathway and has been used in humans with chronic hepatitis $\mathrm{C}$ or inflammatory bowel disease (16). Recombinant IL-10 has had a satisfactory safety profile when administered in other human diseases and is a another candidate for study in autoimmune hepatitis (16). Cytotoxic T lymphocyte antigen-4 fused with immunoglobulin is the most promising intervention in this category because of its relevance to the pathogenic mechanisms of autoimmune hepatitis and its success in other immune-mediated human diseases (16). 


\section{THERAPEUTIC ANIMAL MODELS}

The key to the emergence of new pharmacological and molecular therapies for autoimmune hepatitis is a therapeutic animal model of the human disease (18). Two promising mouse models have emerged while others are also being evaluated. One model is based on the immunization of female mice with plasmids of cytomegalovirus containing the antigenic region of the human cytochrome, CYP2D6, and human formiminotransferase cyclodeaminase (56). These are the antigenic targets of type 2 autoimmune hepatitis. The other model is based on the infection of mice with an adenovirus expressing the antigenic region of human CYP2D6 (57). The infection model has the added advantages of recruiting inflammatory and immune cells to the damaged liver, generating a promiscuous immune response against self-antigens by molecular mimicry and developing extensive hepatic fibrosis. The major deficiencies in these current models are their short life-spans and, as a result, the inability to assess the long-term impact of treatment (18).

\section{THERAPEUTIC DILEMMA}

The new nonstandard drugs for autoimmune hepatitis create a treatment dilemma (58). Ideally, an international collaborative network of committed clinical investigators will be formed, funding resources will be available and large, rigorously designed clinical trials will be launched that fully define the value and role of these new agents. The quandary is whether to wait for more evidence or to treat with these new agents now. For autoimmune hepatitis and other uncommon diseases, expectations for clinical trials have been difficult to realize, and the promising new drugs warrant prudent, highly individualized and timely treatment decisions that are now applicable to clinical practice.

Budesonide in combination with azathioprine can be considered as a front-line therapy, and it may be especially appropriate in treatmentnaive patients with mild, early stage disease or with obesity, osteopenia, diabetes or hypertension that might be worsened by prednisone treatment. A calcineurin inhibitor (cyclosporine or tacrolimus) might be considered for refractory liver disease; mycophenolate mofetil appears to be best suited for patients with azathioprine intolerance.

The treatment dilemma in autoimmune hepatitis requires clinical judgment that is based on the immediacy of the clinical situation, failure of conventional treatment options, knowledge of the new agents and restriction of the new therapies to well-defined clinical situations that can be closely monitored. The societal need for fully evaluated new treatments stresses the need for a continuing effort to introduce new agents to standard clinical practice only after rigorous investigational scrutiny (58).

DISCLOSURES: Presented in part during the Canadian Digestive Diseases Week and annual winter meeting of the Canadian Association for the Study of the Liver, Montreal, Quebec, February 24, 2012. This review did not receive financial support from a funding agency or institution, and Albert J Czaja MD has no conflict of interests to declare.

\section{REFERENCES}

1. Manns MP, Czaja AJ, Gorham JD, et al. Practice Guidelines of the American Association for the Study of Liver Diseases. Diagnosis and management of autoimmune hepatitis. Hepatology 2010;51:2193-213.

2. Cook GC, Mulligan R, Sherlock S. Controlled prospective trial of corticosteroid therapy in active chronic hepatitis. Q J Med 1971;40:159-85.

3. Soloway RD, Summerskill WH, Baggenstoss AH, et al. Clinical, biochemical, and histological remission of severe chronic active liver disease: A controlled study of treatments and early prognosis. Gastroenterology 1972;63:820-33.

4. Murray-Lyon IM, Stern RB, Williams R. Controlled trial of prednisone and azathioprine in active chronic hepatitis. Lancet 1973;1:735-7.

5. Kanzler S, Lohr H, Gerken G, Galle PR, Lohse AW. Long-term management and prognosis of autoimmune hepatitis (AIH): A single center experience. Z Gastroenterol 2001;39:339-41,44-8.

6. Czaja AJ. Rapidity of treatment response and outcome in type 1 autoimmune hepatitis. J Hepatol 2009;51:161-7.

7. Roberts SK, Therneau TM, Czaja AJ. Prognosis of histological cirrhosis in type 1 autoimmune hepatitis. Gastroenterology 1996;110:848-57.

8. Czaja AJ, Carpenter HA. Decreased fibrosis during corticosteroid therapy of autoimmune hepatitis. J Hepatol 2004;40:646-52.

9. Mohamadnejad M, Malekzadeh R, Nasseri-Moghaddam S, et al. Impact of immunosuppressive treatment on liver fibrosis in autoimmune hepatitis. Dig Dis Sci 2005;50:547-51.

10. Czaja AJ. Safety issues in the management of autoimmune hepatitis. Expert Opin Drug Saf 2008;7:319-33.

11. Montano-Loza AJ, Carpenter HA, Czaja AJ. Features associated with treatment failure in type 1 autoimmune hepatitis and predictive value of the model of end-stage liver disease. Hepatology 2007;46:1138-45.

12. Czaja AJ, Davis GL, Ludwig J, Taswell HF. Complete resolution of inflammatory activity following corticosteroid treatment of HBsAg-negative chronic active hepatitis. Hepatology 1984;4:622-7.

13. Hegarty JE, Nouri Aria KT, Portmann B, Eddleston AL, Williams R. Relapse following treatment withdrawal in patients with autoimmune chronic active hepatitis. Hepatology 1983;3:685-9.

14. Czaja AJ, Menon KV, Carpenter HA. Sustained remission after corticosteroid therapy for type 1 autoimmune hepatitis: A retrospective analysis. Hepatology 2002;35:890-7.

15. Czaja AJ. Current and future treatments of autoimmune hepatitis. Expert Rev Gastroenterol Hepatol 2009;3:269-91.
16. Czaja AJ. Emerging opportunities for site-specific molecular and cellular interventions in autoimmune hepatitis. Dig Dis Sci 2010;55:2712-26.

17. Czaja AJ. Promising pharmacological, molecular and cellular treatments of autoimmune hepatitis. Curr Pharm Design 2011;17:3120-40.

18. Czaja AJ. Animal models of autoimmune hepatitis. Expert Rev Gastroenterol Hepatol 2010;4:429-43.

19. Allison AC. Immunosuppressive drugs: The first 50 years and a glance forward. Immunopharmacology 2000;47:63-83.

20. Mistilis SP, Vickers CR, Darroch MH, McCarthy SW. Cyclosporin, a new treatment for autoimmune chronic active hepatitis. Med J Aust 1985;143:463-5.

21. Hyams JS, Ballow M, Leichtner AM. Cyclosporine treatment of autoimmune chronic active hepatitis. Gastroenterology 1987;93:890-3.

22. Person JL, McHutchison JG, Fong TL, Redeker AG. A case of cyclosporine-sensitive, steroid-resistant, autoimmune chronic active hepatitis. J Clin Gastroenterol 1993;17:317-20.

23. Sherman KE, Narkewicz M, Pinto PC. Cyclosporine in the management of corticosteroid-resistant type I autoimmune chronic active hepatitis. J Hepatol 1994;21:1040-7.

24. Jackson LD, Song E. Cyclosporin in the treatment of corticosteroid resistant autoimmune chronic active hepatitis. Gut 1995;36:459-61.

25. Fernandes NF, Redeker AG, Vierling JM, Villamil FG, Fong TL. Cyclosporine therapy in patients with steroid resistant autoimmune hepatitis. Am J Gastroenterol 1999;94:241-8.

26. Malekzadeh R, Nasseri-Moghaddam S, Kaviani MJ, et al. Cyclosporin $\mathrm{A}$ is a promising alternative to corticosteroids in autoimmune hepatitis. Dig Dis Sci 2001;46:1321-7.

27. Van Thiel DH, Wright H, Carroll P, et al. Tacrolimus: A potential new treatment for autoimmune chronic active hepatitis: Results of an open-label preliminary trial. Am J Gastroenterol 1995;90:771-6.

28. Aqel BA, Machicao V, Rosser B, et al. Efficacy of tacrolimus in the treatment of steroid refractory autoimmune hepatitis. J Clin Gastroenterol 2004:38:805-9.

29. Larsen FS, Vainer B, Eefsen M, Bjerring PN, Adel Hansen B. Low-dose tacrolimus ameliorates liver inflammation and fibrosis in steroid refractory autoimmune hepatitis. World J Gastroenterol 2007; 13:3232-6.

30. Allison AC, Eugui EM. Mycophenolate mofetil and its mechanisms of action. Immunopharmacology 2000;47:85-118.

31. Richardson PD, James PD, Ryder SD. Mycophenolate mofetil for maintenance of remission in autoimmune hepatitis in patients resistant to or intolerant of azathioprine. J Hepatol 2000;33:371-5. 
32. Devlin SM, Swain MG, Urbanski SJ, Burak KW. Mycophenolate mofetil for the treatment of autoimmune hepatitis in patients refractory to standard therapy. Can J Gastroenterol 2004;18:321-6.

33. Chatur N, Ramji A, Bain VG, et al. Transplant immunosuppressive agents in non-transplant chronic autoimmune hepatitis: The Canadian Association for the Study of the Liver (CASL) experience with mycophenolate mofetil and tacrolimus. Liver Int 2005;25:723-7.

34. Czaja AJ, Carpenter HA. Empiric therapy of autoimmune hepatitis with mycophenolate mofetil: Comparison with conventional treatment for refractory disease. J Clin Gastroenterol 2005;39:819-25.

35. Inductivo-Yu I, Adams A, Gish RG, et al. Mycophenolate mofetil in autoimmune hepatitis patients not responsive or intolerant to standard immunosuppressive therapy. Clin Gastroenterol Hepatol 2007;5:799-802.

36. Hlivko JT, Shiffman ML, Stravitz RT, et al. A single center review of the use of mycophenolate mofetil in the treatment of autoimmune hepatitis. Clin Gastroenterol Hepatol 2008;6:1036-40.

37. Hennes EM, Oo YH, Schramm C, et al. Mycophenolate mofetil as second line therapy in autoimmune hepatitis? Am J Gastroenterol 2008;103:3063-70.

38. Wolf DC, Bojito L, Facciuto M, Lebovics E. Mycophenolate mofetil for autoimmune hepatitis: A single practice experience. Dig Dis Sci 2009;54:2519-22.

39. Aw MM, Dhawan A, Samyn M, Bargiota A, Mieli-Vergani G. Mycophenolate mofetil as rescue treatment for autoimmune liver disease in children: A 5-year follow-up. J Hepatol 2009;51:156-60.

40. Sharzehi K, Huang MA, Schreibman IR, Brown KA. Mycophenolate mofetil for the treatment of autoimmune hepatitis in patients refractory or intolerant to conventional therapy. Can J Gastroenterol 2010;24:588-92.

41. Baven-Pronk AM, Coenraad MJ, van Buuren HR, et al. The role of mycophenolate mofetil in the management of autoimmune hepatitis and overlap syndromes. Aliment Pharmacol Ther 2011;34:335-43.

42. Zachou K, Gatselis N, Papadamou G, Rigopoulou EI, Dalekos GN. Mycophenolate for the treatment of autoimmune hepatitis: Prospective assessment of its efficacy and safety for induction and maintenance of remission in a large cohort of treatment-naive patients. J Hepatol 2011;55:636-46.

43. Seikaly MG. Mycophenolate mofetil - is it worth the cost? The in-favor opinion. Pediatr Transplant 1999;3:79-82.
44. Heneghan MA, Al-Chalabi T, McFarlane IG. Cost-effectiveness of pharmacotherapy for autoimmune hepatitis. Expert Opin Pharmacother 2006;7:145-56.

45. Czaja AJ. Mycophenolate mofetil to the rescue in autoimmune hepatitis: A fresh sprout on the decision tree. J Hepatol 2009;51:8-10.

46. Clissold SP, Heel RC. Budesonide. A preliminary review of its pharmacodynamic properties and therapeutic efficacy in asthma and rhinitis. Drugs 1984;28:485-518.

47. Manns MP, Woynarowski M, Kreisel W, et al. Budesonide induces remission more effectively than prednisone in a controlled trial of patients with autoimmune hepatitis. Gastroenterology 2010;139:1198-206.

48. Danielsson A, Prytz H. Oral budesonide for treatment of autoimmune chronic active hepatitis. Aliment Pharmacol Ther 1994;8:585-90.

49. Czaja AJ, Lindor KD. Failure of budesonide in a pilot study of treatment-dependent autoimmune hepatitis. Gastroenterology 2000;119:1312-6.

50. Wiegand J, Schuler A, Kanzler S, et al. Budesonide in previously untreated autoimmune hepatitis. Liver Int 2005;25:927-34.

51. Csepregi A, Rocken C, Treiber G, Malfertheiner P. Budesonide induces complete remission in autoimmune hepatitis. World J Gastroenterol 2006;12:1362-6.

52. Zandieh I, Krygier D, Wong V, et al. The use of budesonide in the treatment of autoimmune hepatitis in Canada. Can J Gastroenterol 2008;22:388-92.

53. Geier A, Gartung C, Dietrich CG, et al. Side effects of budesonide in liver cirrhosis due to chronic autoimmune hepatitis: Influence of hepatic metabolism versus portosystemic shunts on a patient complicated with HCC. World J Gastroenterol 2003;9:2681-5.

54. Lohse AW, Gil H. Reactivation of autoimmune hepatitis during budesonide monotherapy, and response to standard treatment. J Hepatol 2011;54:837-9.

55. Czaja AJ, Manns MP. Advances in the diagnosis, pathogenesis and management of autoimmune hepatitis. Gastroenterology 2010;139:58-72.

56. Lapierre P, Djilali-Saiah I, Vitozzi S, Alvarez F. A murine model of type 2 autoimmune hepatitis: Xenoimmunization with human antigens. Hepatology 2004;39:1066-74.

57. Holdener M, Hintermann E, Bayer M, et al. Breaking tolerance to the natural human liver autoantigen cytochrome P450 2D6 by virus infection. J Exp Med 2008;205:1409-22.

58. Manns MP. Autoimmune hepatitis: The dilemma of rare diseases. Gastroenterology 2011;140:1874-6. 


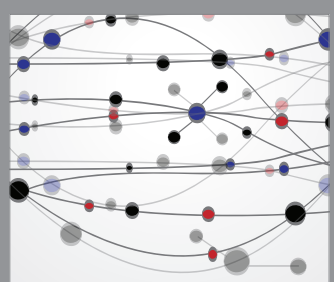

The Scientific World Journal
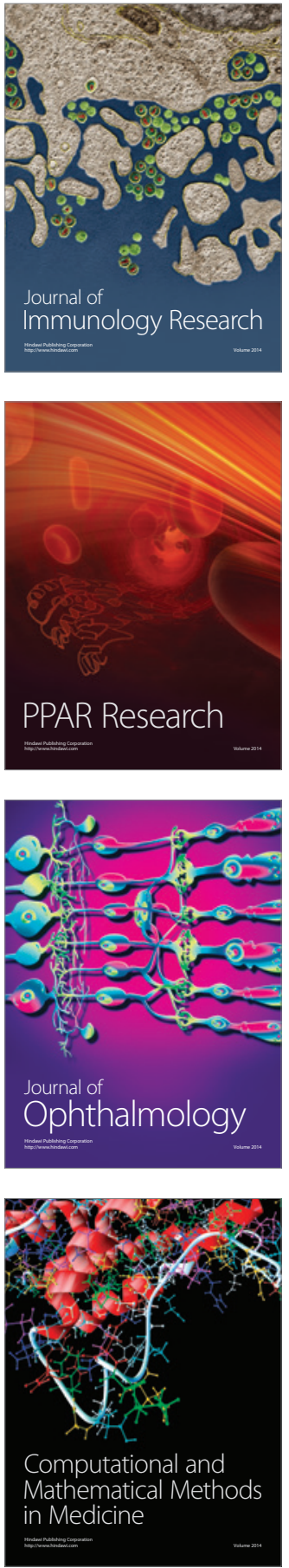

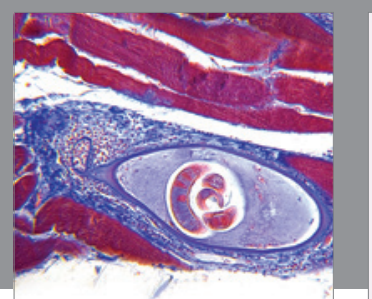

Gastroenterology Research and Practice

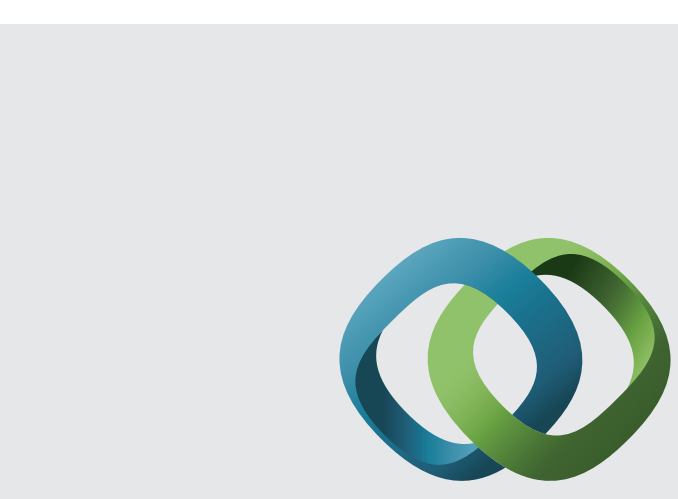

\section{Hindawi}

Submit your manuscripts at

http://www.hindawi.com
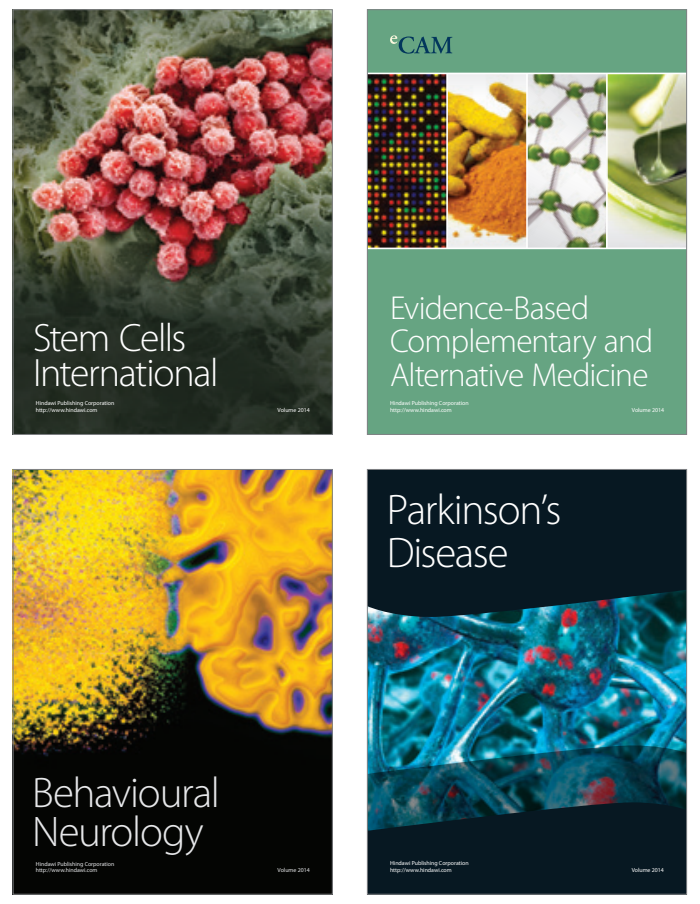
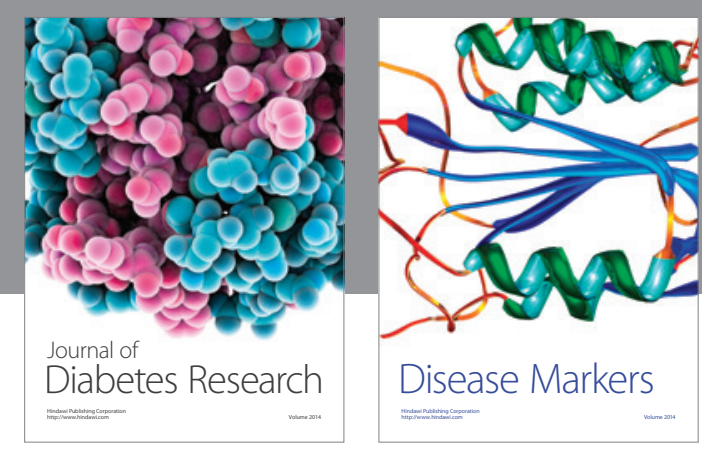

Disease Markers
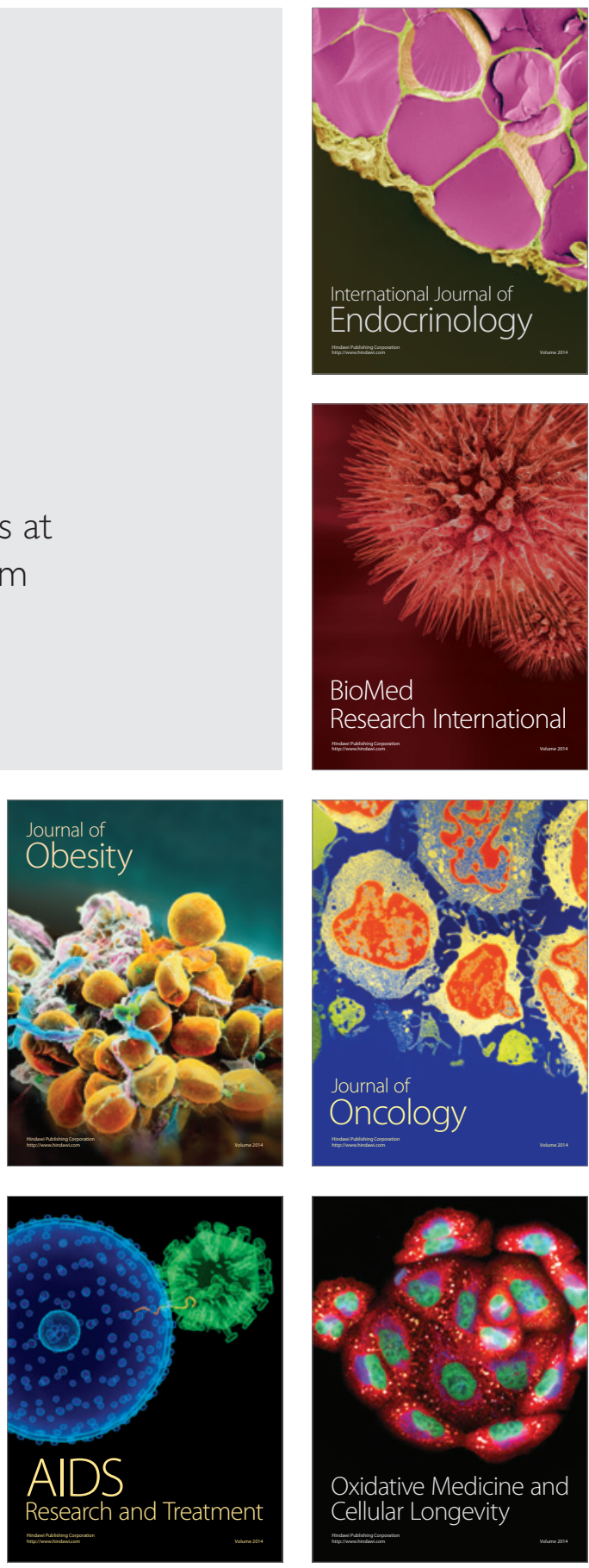